\title{
RELAÇÕES ENTRE IRMÃOS: IMPACTO DA RIVALIDADE NA GESTÃO'
}

\section{Sibling relationships: impact of rivalry in management}

Mara Vogt

E-mail: maravogtcco@gmail.com

Mestre em Ciências Contábeis pela Fundação Universidade Regional de Blumenau; Doutoranda em Ciências Contábeis pela Fundação Universidade Regional de Blumenau; Bolsista na Fundação

Universidade Regional de Blumenau

Endereço para contato: Rua Antônio da Veiga, 140, Victor Konder, 89030-903, Blumenau, Santa

Catarina, Brasil.

http://orcid.org/0000-0002-3951-4637

Juçara Haveroth

E-mail: jucarahaveroth@hotmail.com

Mestre em Ciências Contábeis pela Fundação Universidade Regional de Blumenau; Doutoranda em Ciências Contábeis pela Fundação Universidade Regional de Blumenau; Bolsista na Fundação

Universidade Regional de Blumenau. https://orcid.org/0000-0001-7327-0667

Vinícius Costa da Silva Zonatto

E-mail:viniciuszonatto@gmail.com

Doutor em Ciências Contábeis pela Fundação Universidade Regional de Blumenau; Mestre em Ciências Contábeis pelaFundação Universidade Regional de Blumenau; Professor na Universidade

Federal de Santa Maria. https://orcid.org/0000-0003-0823-6774 
O estudo objetiva descrever os impactos causados pela rivalidade entre irmãos na gestão de empresas familiares. Realizou-se uma pesquisa descritiva por meio de estudo de caso e com uma abordagem qualitativa dos dados. Os resultados revelaram que a rivalidade já esteve presente na empresa familiar analisada desde seu processo sucessório em razão da diferença das quotas referentes à sociedade, e com o passar do tempo, começou a aflorar na empresa rivalidade entre irmãos e todos os demais membros. Por conta disso, começaram os questionamentos sobre a gestão, a desconfiança, o envolvimento de fatores externos e internos que influenciavam. Outro fator determinante para o aumento da rivalidade foi a presença das esposas na gestão da empresa familiar. Conclui-se que a rivalidade impacta de forma negativa os resultados das organizações familiares, especialmente nos casos que envolvem outras pessoas da família no negócio e que não conseguem separar a tríade (negócio, família e propriedade). A gestão é influenciada também pela falta de inteligência emocional dos membros, fazendo com que a organização sofra e apresente problemas, incluindo a dissolução.

Palavras-chave: Empresas familiares. Rivalidades. Irmãos. Cônjuges. Gestão.

\section{Abstract}

The study aims to describe the impacts caused by sibling rivalry in family business management. A descriptive exploratory study was carried out, through a case study and a qualitative approach of the data. The results revealed that the rivalry was already present in the family business analyzed since its succession process, due to the difference of the quotas referring to the society and with the passage of time, began to appear in the company the rivalry between the brothers and all the other members. As a result, questions about management, mistrust, the involvement of external and internal factors began to influence. Another determining factor for the increase in rivalry was the presence of wives in the management of the family business. It is concluded that rivalry has a negative impact on the results of family organizations, especially in cases involving other family members in the business and who can not separate the triad (business, family and property). Management is also influenced by the lack of emotional intelligence of the members, causing the organization to suffer and present problems, including dissolution.

Keywords: Family business. Rivalries. Brothers. Spouses. Management.

\section{INTRODUÇÃO}

A família é o alicerce fundamental na vida de todos os seres humanos. Para tanto, um bom relacionamento intrafamiliar é essencial para o bom desempenho da gestão de qualquer empresa familiar. Não é à toa que empresas familiares representam a forma mais comum de negócios na economia mundial (Nordqvist \& Melin, 2010). Assim, desde a década de 1980 as pesquisas sobre empresas familiares se intensificaram e têm percorrido uma longa trajetória (Astrachan \& Jaśkiewicz, 2008; Gómez-Mejía, Haynes, Núñez-Nickel, Jacobson \& Moyano-Fuentes 2007; Zellweger \& Astrachan, 2008; Gómez-Mejía, Cruz, Berrone \& Castro, 2011; Labaki, Michael-Tsabari \& Zachary, 2013). 
Diante do exposto, é amplamente notável que as empresas familiares possuem algumas características que as diferem das demais empresas, sendo que a característica mais marcante se refere a presença de emoções decorrentes do envolvimento familiar na gestão dos negócios da família (Kellermanns, Dibrell \& Cruz, 2014). A tríade família, negócios e propriedade gera situações na qual o controle das emoções pode ser, ou se tornar um ponto de inflamação que afeta a harmonia familiar e consequentemente a gestão, devido aos conflitos entre seus membros (Gómez-Betancourt, Ramírez, \& Vergara, 2013).

Destaca-se que a combinação de esferas familiares e empresariais cria um ambiente propício às diferenças, desentendimentos e tensões, sendo que os conflitos no sistema familiar podem afetar negativamente o funcionamento e a eficácia dos negócios (Pieper, 2010). Como exemplo das tensões existentes em empresas familiares, destaca-se a presença de rivalidade, competitividade, ganância, entre outros aspectos.

Contudo, ressalta-se que não está consolidada na literatura a forma com que essas emoções impactam a tomada de decisão do negócio da família (Kellermanns, Dibrell, \& Cruz, 2014). Ainda, as emoções podem ser uma consequência do desejo de proteger e preservar a empresa familiar no longo prazo, o que pode refletir indiretamente na tomada de decisões (Morgan \& Gómez-Mejía, 2014). Nesse sentido, faz-se necessário que os sucessores estejam preparados para dar continuidade ao negócio familiar, pois a sobrevivência da empresa está diretamente ligada a essa preparação. Para tanto, o sucessor deve buscar a qualificação adequada e conhecimentos da prática profissional da empresa, sendo amparado pelos conhecimentos sobre gestão (Tillmann \& Grzybovski, 2005).

O interesse de todos os indivíduos que estão diretamente ligados à gestão da empresa familiar deve ser unificado, objetivando melhorar a eficácia da empresa, buscando, inclusive, o entendimento de como os conflitos podem ser geridos (Friedman, 1991). Exemplificando, no momento em que um dos irmãos assume a gestão, é preciso saber lidar com as necessidades individuais de cada um dos membros, de modo a evitar eventuais conflitos de interesses que causem rivalidades, o que acaba prejudicando toda a organização. Existindo rivalidade entre irmãos, esta pode ser maligna ou benigna. Se for maligna, pode destruir a empresa, pois irmãos não têm liberdade para escolher seus papéis familiares. Já se for benigna, pode auxiliar a gestão em razão da competição, possibilitando novas perspectivas organizacionais, cooperando nos melhores interesses de sua empresa familiar (Friedman, 1991).

Por mais que a academia tenha passado a reconhecer a importância dos estudos no âmbito de empresas familiares (Lindow, Stubner, \& Wulf, 2010), as pesquisas sobre negócios familiares têm progredido estreitamente quanto à base teórica de emoções dos membros e ao seu potencial impacto na gestão (Astrachan \& Jaśkiewicz, 2008; Gómez-Mejía, Haynes, Núñes-Nickel, Jacobson, \& Moyano-Fuentes, 2007; Zellweger \& Astrachan, 2008). Dentro de todo esse conjunto de pesquisas sobre empresas familiares, a sucessão tem sido uma das temáticas favoritas (Reyna \& Encalada, 2016). Contudo, poucas são as pesquisas que têm 
explorado os problemas anteriores à própria sucessão familiar, como é o caso dos conflitos e rivalidades entre irmãos, foco deste estudo.

Buscas realizadas sobre a temática de rivalidades entre irmãos na gestão familiar foram realizadas em diferentes bases nacionais, como SPELL, Scielo, Portal Capes, Google Acadêmico, e internacionais, como Scopus, Science Direct, RCAAP e Web of Science; não foram localizados estudos que tenham verificado essa problemática. Isso se confirma com o exposto por Kilduff, Elfenbein, e Staw em seu estudo publicado no ano 2010, de que os pesquisadores têm dado pouca atenção no que diz respeito à rivalidade na gestão de empresas familiares. Sabendo que esse é um dos principais motivos para a dissolução das empresas familiares, nota-se uma lacuna de investigação para esse contexto.

Frente ao exposto, o estudo tem como propósito responder à seguinte questão: Como a rivalidade entre irmãos impacta a gestão de empresas familiares? Com o intuito de responder a essa questão de pesquisa, tem-se como objetivo descrever os impactos causados pela rivalidade entre irmãos na gestão de empresas familiares.

Justifica-se o estudo pois empresas familiares precisam ser analisadas sob outras perspectivas, e, com mais profundidade sobre os aspectos comportamentais, como, por exemplo, os conflitos e as rivalidades existentes entre os membros familiares. Além disso, vale destacar que essas empresas não sofrem apenas os problemas típicos das demais empresas, pois há a questão familiar envolvida no processo (Reyna \& Encalada, 2016).

Destaca-se que rivalidades podem advir de aspectos psicológicos como emoções, além de princípios, valores e competição (Maccari, Campanário, Almeida, \& Martins, 2006; Kilduff, Elfenbein, \& Staw, 2010). Portanto, a importância de estudar as rivalidades justificase pelo fato de que empresas familiares não podem resolver questões como a sucessão, por exemplo, sem uma avaliação honesta das rivalidades familiares, pois estas desviam a atenção da gestão quanto aos processos, prejudicando a visão de futuro da organização (Grote, 2003).

Para Massis e Kotlar (2014), a empresa familiar é um campo heterogêneo que abrange diversas abordagens teóricas e níveis de análise, sendo que essa diversidade pode e deve ser refletida na forma como os estudos de caso são aplicados. Para tanto, justifica-se a partir desses autores que estudos de caso apresentam uma metodologia poderosa e que esta pode ser usada de uma forma criativa e abrangente, buscando sempre avançar nas pesquisas sobre a temática das empresas familiares.

Além disso, o estudo de caso torna-se um método valioso para os estudiosos de empresas familiares descreverem fenômenos complexos, desenvolverem novas teorias ou, até mesmo, para refinarem e ampliarem as teorias já existentes (Massis \& Kotlar, 2014). Os autores ressaltam que as empresas familiares fornecem um contexto único e especial para o trabalho de estudo de caso, ainda mais ao estenderem ou enriquecerem as perspectivas 
comportamentais (Massis \& Kotlar, 2014), como é o caso deste estudo, olhando para um aspecto do comportamento, a rivalidade presente na gestão.

Assim, destaca-se que o estudo, sob essa perspectiva proposta, é inovador e essencial para discussões e aprofundamento sobre o tema em razão do fato de olhar sob perspectivas pouco investigadas em empresas familiares, fornecendo evidências do impacto que pode ser gerado pela rivalidade na gestão das empresas familiares. Portanto, compreender suas relações no contexto do trabalho contribui para o entendimento de fatores determinantes da gestão.

\section{REVISÃO DA LITERATURA}

Na revisão da literatura são expostos e discutidos os dois principais aspectos para auxiliar o embasamento desta pesquisa. Inicialmente foram elencadas características que definem as empresas familiares e as diferenciam das empresas não familiares. Na sequência, discorre-se sobre as rivalidades presentes em empresas familiares.

\subsection{EMPRESAS FAMILIARES}

É seguro afirmar que não existem duas empresas familiares iguais (Levinson, 1983). As empresas familiares são instituições reconhecidamente diferenciadas, visto que, ao contrário de outros tipos de organizações, seu ciclo de vida geralmente é determinado pelo quanto a tríade família, empresa e gestão estão bem estruturadas (Andrade, Grzybovski, \& Lima, 2004). Essencialmente a diferença das empresas familiares para as que não são é determinada pelo papel que a família tem sobre as operações como um todo (Atalay \& Özler, 2013).

Sabe-se que no Brasil as empresas familiares são as grandes responsáveis pela movimentação da economia, sendo inegável sua importância na forma política, social, cultural e econômica (Estol \& Ferreira, 2006; Paiva \& Melo, 2008). Além disso, existem também o envolvimento e a visibilidade social da família, sendo esta elemento-chave para o desempenho financeiro (Athanassiou, Crittenden, Kelly, \& Marquez, 2002). A mentalidade da família pode alterar os processos de tomada de decisão na empresa e os conflitos que surgem nestas. Isso também ocorre em empresas não familiares, no entanto, de forma diferente (Webb, Ketchen, \& Ireland, 2010).

Desse modo, pode-se pensar nos subsistemas de empresa familiar considerando a família como entidade. Nesse caso, deve-se considerar que cada membro da família tem uma identidade e uma cultura própria, o que, por sua vez, desperta necessidades e valores competitivos. Isso torna a empresa familiar um conjunto complexo tanto de relacionamentos 
quanto de gerenciamento, emergindo a ideia de que a continuidade pode ser uma tarefa difícil (Beckhard \& Dyer, 1983).

Apesar de toda sua relevância, as empresas familiares são permeadas por um antagonismo de interesses e ações, visto que os sócios podem não estar dispostos a assumir riscos e acabar colocando o desempenho da organização em perigo (Gómez-Mejía et al., 2007). Para melhor atender ao objetivo quanto às melhores práticas de negócio da família, faz-se necessário profissionalizar a gestão e, assim, saber lidar com o crescimento e a complexidade das relações decorrentes de processos institucionais (Dana \& Smyrnios, 2010).

Nesse caso, todas as questões dentro da empresa familiar devem ser consideradas e analisadas, como: estágio de desenvolvimento da empresa, cultura da organização, normas, tradições, cultura familiar, influência da família no fundador, influência das motivações e valores pessoais dos fundadores ou proprietários (Beckhard \& Dyer, 1983). Desse modo, o grupo de tomada de decisão do controle familiar é responsável por alterar as decisões e a forma como estas são tomadas, assim como determinar a forma na qual os resultados serão alcançados (Webb et al., 2010).

Entretanto, com o surgimento dos conflitos, e, quando estes não são tratados devidamente, acabam aumentando as chances de que a empresa sofra diversas consequências, culminando em casos extremos no seu processo de dissolução (Moreira, 2006). Sabe-se que um dos princípios das organizações é o princípio da continuidade e, sabendo que a minoria das empresas familiares tem conseguido legar à empresa a seus descendentes, sem maiores dificuldades, o tema empresas familiares é, muitas vezes, visto como um tema paradoxal (Reyna \& Encalada, 2016). Desse modo, fica evidenciado que relações de negócios envolvendo a família são mais complexas.

O conflito pode não ser sempre uma indicação de desacordo e vontade de dividir maneiras. Pelo contrário, o conflito pode ser uma indicação de que os proprietários realmente querem ficar juntos e lutam com a mesma intensidade que ocorre no processo da separação (Pieper, 2010). Quando os interesses pessoais falam mais alto, podem se transformar em problemas, dificultando a sobrevivência das empresas (Moreira, 2006). Essas situações acontecem de acordo com as relações existentes entre os irmãos, bem como cônjuges ou familiares, especialmente se estes tiverem algum interesse particular no negócio, transformando tensões em desequilíbrios difíceis de serem contornados.

\subsection{RIVALIDADE EM EMPRESAS FAMILIARES}

Operar uma empresa familiar é considerado, por diversas vezes, um trabalho complicado em decorrência dos conflitos que são inerentes às relações familiares, como 
disputa de poder, ambição pessoal, rivalidade, individualismo, competição, além da dificuldade em conseguir separar a família do negócio (Levinson, 1971).

Muitas vezes esses conflitos podem levar a situações extremas, como a dissolução da sociedade ou até mesmo a falência em casos em que os conflitos não são geridos há tempo de solucionar os problemas existentes na organização. Um desses conflitos frequentemente percebidos em empresas familiares é a rivalidade, que pode ser observada nas relações entre membros da família como pais e filhos, cônjuges, irmãos e outros parentes (Levinson, 1971).

Para Kilduff et al. (2010), como rivalidade se considera uma relação de concorrência subjetiva entre atores, que implica um maior envolvimento psicológico, independente das características objetivas da situação em que se encontram. De acordo com esse conceito existe rivalidade quando é colocada maior relevância na competição contra outro agente. Ainda, conforme os autores, a rivalidade é percebida à medida que existe uma outra relação além da concorrência, sendo esta subjetiva (Kilduff et al., 2010; Maccari et al., 2006). No caso deste estudo, a rivalidade é estudada no âmbito das relações familiares.

Andrade, Rezende, e Rezende (2003) expõem, de forma resumida, que a rivalidade ocorre à medida que dois ou mais irmãos acabam discordando no que diz respeito à política da organização e seus respectivos papéis no negócio. Além disso, outra questão latente para a ocorrência do conflito é o momento em que os filhos começam a se casar e entram novas pessoas para a família, bem como na empresa familiar. A partir do momento que esses novos membros da família trazem consigo diferentes ideais, intensifica-se o conflito já existente, tornando ainda mais complexo o processo sucessório.

Nesse contexto, um processo de sucessão pode ser uma experiência problemática e traumática, mesmo que seja planejado, visto que podem emergir as rivalidades entre os membros da família em decorrência dos conflitos entre o sucedido e o sucessor, ou seja, entre pai e herdeiros (Morris, Williams, \& Nel, 1996). Uma pesquisa realizada por Scheffer (1995) identificou os fatores principais que dificultam a sucessão e, entre estes, tem-se a rivalidade entre familiares pela posse do controle do negócio da família. Vale frisar que, segundo Morris et al. (1996), rivalidade é um fenômeno psicológico que assume uma importância notável no comportamento dos membros da empresa familiar.

Ressalta-se que nem sempre a rivalidade é disfuncional para o negócio da família (Sharma, Chrisman, \& Chua, 1997). Para os autores, os pesquisadores têm assumido que o que é bom para a harmonia da família é bom para o negócio, mas isso nem sempre é verídico. Para isso, é preciso que os membros da empresa familiar entendam os trade-offs envolvidos na manutenção da harmonia dentro da família como um todo, sendo esse o ponto que separa uma gestão bem-sucedida de outra fracassada.

Nesse mesmo sentido, Lodi (1986) salienta que um dos motivos para o fracasso da empresa familiar é a rivalidade entre irmãos que desorienta os profissionais, visto que, com 
ela, perde-se um tempo demasiado com perturbações e tentativas frustradas de negociar o inegociável. Ainda, sabe-se que muitos fracassos em empresas familiares se devem aos conflitos ocasionados pelas rivalidades. Stocker e Youngblade (1999) verificaram, a partir de seu estudo, que o conflito e a rivalidade entre irmãos podem ser muito irritantes $e$ estressantes, estendendo-se a conflitos conjugais, o que diminui a oportunidade de uma expressão afetuosa entre as famílias dos membros.

Da mesma forma, Reid, Dunn, Cromie, e Adams (1999) aduzem que a rivalidade entre irmãos pode levar a rompimentos de relações familiares, afetando negativamente a saúde da organização. Outro conflito que pode estar relacionado com os negócios familiares é o conflito conjugal (Stocker \& Youngblade, 1999). Estes autores verificaram, a partir dos resultados de sua pesquisa, que o conflito conjugal esteve significativamente associado com maiores conflitos e rivalidades entre irmãos, ou seja, o fato de haver cônjuges envolvidos na empresa familiar eleva ainda mais os conflitos existentes.

Sob essa perspectiva, Levinson (1983) já destacava em seu estudo que muitas vezes outros membros como os cônjuges acabam adentrando no negócio familiar e ocupam diferentes cargos na organização, por mais que não sejam os sucessores. Com relação à rivalidade, o autor elucida que esta pode estar relacionada ao passado da relação familiar, por um irmão ter mais vantagens que os demais, ficando como um negócio malresolvido no inconsciente do indivíduo e que pendurará por muito tempo (Levinson, 1983).

Cabe destacar que existem pressões poderosas para os irmãos negarem a existência de uma rivalidade no seu relacionamento, e essas pressões acabam inibindo a possibilidade de um ambiente constantemente sadio entre suas relações pessoais e empresariais, o que depende somente dos próprios membros. Porém, por mais que rivalidade seja um conflito remanescente da infância, ao atingirem a idade adulta os irmãos podem alterar esses seus relacionamentos, escolhendo se devem assumir atitudes colaborativas ou competitivas (Friedman, 1991), o que, por consequência, refletirá nas decisões tomadas e nos resultados do negócio familiar.

A partir do contexto apresentado anteriormente, deve-se considerar que a rivalidade é subjetiva e existe nas mentes dos concorrentes, ou seja, dos membros das empresas familiares (Kilduff et al., 2010). Diante do exposto, entende-se que as rivalidades podem afetar os resultados das empresas, em especial no caso das empresas familiares. Isso porque esse tipo de organização possui maiores relações afetivas, o que consequentemente aumenta o desejo em se estar em um ambiente harmonioso e que tenha maiores chances de sucesso e continuidade dos negócios. 


\section{METODOLOGIA}

Este estudo é caracterizado como um estudo de caso, com natureza descritiva e abordagem qualitativa dos dados. Para tanto, o estudo de caso foi realizado com uma empresa familiar de médio porte, com representatividade no contexto social da qual fazia parte e localizada no Estado de Santa Catarina. A escolha dessa empresa foi intencional e não probabilística, sendo considerada adequada para o contexto da pesquisa em razão do fato de ter passado por um processo recente de dissolução, e, ainda, por ter atuado por um longo período no mercado de trabalho, ou seja, de 1964 a 2016. Além disso, ressalta-se que - acesso aos membros da empresa também viabilizou a realização da coleta de dados para posterior consecução do estudo.

Assim, o estudo de caso iniciou com a aplicação de um questionário fechado, que foi elaborado por meio do Google Docs e enviado por e-mail aos membros da empresa familiar que atuavam nos cargos de gestão e suas respectivas esposas, sendo que foram enviados seis questionários e, destes, obteve-se as respostas de cinco. Destaca-se que esse procedimento foi adotado com vistas a identificar algumas percepções dos pesquisados para posterior aprofundamento a partir das entrevistas.

Dividiu-se o questionário em seis blocos: Bloco I, que indaga sobre o perfil dos respondentes (quatro questões); Bloco II, sobre o processo de sucessão da empresa (nove questões) com base em Grote (2003), Pieper (2010), Gómez-Mejía et al. (2011) e GómezBetancourt et al. (2013); Bloco III, com relação aos problemas familiares (cinco questões) pautadas em Grote (2003) e Pieper (2010); e Bloco IV, no que tange aos sentimentos dos gestores durante o processo de declínio das relações formadas na empresa (nove questões) baseadas em Grote (2003), Van den Heuvel, Goel, Gils, e Voordeckers (2007), Astrachan e Jaśkiewicz (2008) e Gómez-Betancourt et al. (2013).

No total foram 27 perguntas para o questionário, as quais puderam ser acessadas pelos respondentes por meio do link https://goo.gl/forms/4a8l7HnuonHqoGm12. De forma complementar, foi desenvolvida a entrevista baseada em Grote (2003) e Astrachan e Jaśkiewicz (2008), a qual foi composta por 13 questões que estão dispostas no Apêndice, além das questões sobre o perfil da empresa.

De posse dos dados coletados a partir da aplicação dos questionários, identificouse elementos-chave de análise, relacionados aos sentimentos relatados pelos sujeitos da pesquisa, como conflitos familiares que emergiram na sociedade, sua influência nos processos de sucessão e gestão e nas relações familiares estabelecidas entre os membros dessa organização. Esses elementos constituíram as principais categorias de análise observadas nesta pesquisa. 
Com o intuito de garantir a confiabilidade e visando à robustez dos achados, realizouse a triangulação dos dados mediante a análise de documentos, a partir dos questionários, das entrevistas realizadas em profundidade e das observações in loco. Ressalta-se que de acordo com Martins (2006), a triangulação dos dados em pesquisas qualitativas se refere à "utilização de várias fontes de evidências, sendo que a significância dos achados terá mais qualidade ainda se as técnicas forem distintas" (p. 80).

Para tanto, como primeira etapa da coleta de dados, aplicou-se o questionário. $\mathrm{Na}$ sequência foram realizadas as entrevistas em profundidade com cada um dos três membros, sócios da empresa pesquisada e, ainda, com suas respectivas esposas. No momento da realização das entrevistas também foram realizadas observações junto aos entrevistados para identificar expressões de comportamento que não seriam possíveis e percebidas de outra forma e que poderiam auxiliar na interpretação dos resultados das entrevistas. Ressalta-se que as questões que compõem a entrevista são apresentadas no Apêndice deste trabalho. Por fim, analisaram-se diversos documentos como: contrato, distrato e relatórios gerenciais que foram disponibilizados pelos entrevistados no momento da realização das devidas entrevistas.

Ainda com relação às entrevistas estas foram agendadas previamente e realizadas in loco, com os membros sócios e suas esposas na cidade em que a empresa está localizada. Todas as entrevistas foram gravadas com o consentimento dos envolvidos, sendo que após sua devida transcrição foram encaminhadas a cada um dos entrevistados para confirmar suas declarações, retificar afirmativas ou, ainda, complementar trechos quanto aos seus relatos. $O$ tempo médio da realização das entrevistas foi de 30 minutos, contudo, o tempo mínimo de uma entrevista foi de 15 minutos (com uma esposa de um dos sócios) e o tempo máximo foi de 60 minutos (com um dos sócios). O tempo total de duração das entrevistas foi de três horas.

Para assegurar o anonimato dos entrevistados, levando em consideração os requisitos éticos, não foram divulgados os nomes dos respondentes, bem como o nome da organização, sendo esses dados utilizados somente para fins de tratamento e organização da pesquisa. O conjunto de procedimentos que foi adotado tanto na etapa de coleta quanto na de análise dos dados foi o corpus da pesquisa, sendo essencial para a melhor compreensão das informações. Isso porque se buscou a verificação bem como a legitimidade das informações, o que confere maior confiabilidade ao estudo, demonstrando coerência entre os instrumentos utilizados e as devidas evidências encontradas.

\section{ANÁLISE DOS DADOS}

A empresa na qual se realizou o estudo de caso é uma referência de empresa familiar no Estado de Santa Catarina, isso porque é exportadora no ramo madeireiro e, além disso, 
uma empresa familiar antiga que foi constituída em 1964. Sua forma jurídica de Sociedade por Quotas de Responsabilidade Limitada era tributada pelo Lucro Presumido. Enfatiza-se que no último ano de atuação, isto é, em 2016, a empresa contava com aproximadamente 125 funcionários. Naquele momento a empresa estava em sua terceira geração familiar e era conduzida por três irmãos, que compunham a sociedade. Por meio das entrevistas e da mesma forma, a partir da verificação documental, no Contrato Social da empresa verificouse que os três sócios possuíam diferentes quotas de capital.

A diferença das quotas não é significativa e foi repassada dessa forma aos filhos pelo pai, tendo como critério a idade de cada filho. Contudo, por mais que esse tenha sido um critério do pai, vale destacar que nesse momento já podia ter se iniciado uma possível rivalidade entre irmãos, ou até mesmo antes de assumirem a empresa familiar, a partir de fatos ocorridos na própria família. Além disso, por mais que depois da primeira sucessão familiar todos os filhos passaram a ocupar cargo de sócio-gerente, exerciam funções distintas uns dos outros:

a) Sócio 1: responsável pelo controle e aquisição de matéria-prima;

b) Sócio 2: responsável pela parte administrativa, fabricação de móveis e exportação;

c) Sócio 3: responsável pelo controle e manutenção da serraria.

\subsection{PERFIL DOS RESPONDENTES}

Na sequência, apresenta-se o perfil dos cinco respondentes membros da empresa, obtido a partir das respostas do questionário. As perguntas sobre o perfil correspondem a idade, escolaridade, cargo e tempo de atuação, conforme exposto na Tabela 1:

Tabela 1

Perfil dos respondentes

\begin{tabular}{lcccc}
\hline \multicolumn{1}{c}{ Membros } & Idade & Escolaridade & Cargo & Tempo de atuação \\
\hline Sócio 1 & 50 anos & Ensino Médio Incompleto & Sócio-gerente & 38 anos \\
\hline Esposa Sócio 1 & 49 anos & Ensino Médio Completo & Auxiliar de Escritório & 25 anos \\
\hline Sócio 2 & 47 anos & Ensino Médio Completo & Sócio-gerente & 30 anos \\
\hline Sócio 3 & 37 anos & Ensino Médio Completo & Sócio-gerente & 25 anos \\
\hline Esposa Sócio 3 & 37 anos & Ensino Superior Completo & Secretária & 8 anos \\
\hline
\end{tabular}

Nota-se que os membros da empresa familiar analisada apresentavam uma idade entre 37 e 50 anos. $O$ membro com maior idade refere-se ao Sócio l, sendo este o que possuía a maior quota da sociedade, ensino médio completo e atuava na empresa durante 38 anos. 
No entanto, a escolaridade desse gestor não comprometeu o exercício da sua função, por mais que tivesse a menor escolaridade entre os membros da empresa analisada.

O Sócio 2, de 47 anos, informou que possuía ensino médio completo e também atuava na empresa durante 30 anos. Já o Sócio 3 é o mais novo entre os irmãos, com 37 anos e tempo de atuação na empresa familiar de 25 anos. Somente um dos irmãos e uma esposa (Esposa Sócio 3) possuíam ensino superior completo, sendo que esta atua há apenas oito anos na empresa analisada. Já a Esposa do Sócio 1 assume o cargo de Auxiliar de Escritório e a Esposa do Sócio 3 de Secretária.

\subsection{PROCESSO DE SUCESSÃO}

A partir da Tabela 2 serão apresentadas as respostas dos membros da organização concedidas à entrevista sobre seu entendimento com relação à gestão, se era similar entre os membros ou diferente. Destaca-se que foram evidenciados apenas os trechos considerados essenciais para responder às perguntas realizadas, até porque a sucessão foi utilizada no estudo para entender o momento, geração em que a empresa se encontra, bem como quais os problemas no processo sucessório poderiam estar impactando e causando ou aumentando a rivalidade entre irmãos. Assim, as respostas foram utilizadas como complemento e para dar maior robustez à análise.

Tabela 2

Respostas com relação à forma de gerir a organização entre os irmãos

\begin{tabular}{|c|c|}
\hline Membros & Respostas com relação à forma de gerir a organização entre os irmãos \\
\hline Sócio 1 & $\begin{array}{l}\text { Nós somos três irmãos dentro da família. Eu e o Sócio } 3 \text { temos um tipo de decisão, mas } \\
\text { temos um irmão (Sócio 2) que é diferente de nós, tem outro jeito de administrar. }\end{array}$ \\
\hline Esposa Sócio 1 & na verdade, dois são mais parecidos e um era diferente. \\
\hline Sócio 2 & $\begin{array}{l}\text { Era, é ... sempre foi diferente. Por isso que cada um tocava um setor, cada um admi- } \\
\text { nistrava uma parte da empresa... . Cada um cuidava bem da sua área e não misturava, } \\
\text { assim, sempre dava certo. }\end{array}$ \\
\hline Sócio 3 & $\begin{array}{l}\text { Sempre tinha um irmão que tinha uma ideia de uma maneira, o outro, de outra, outro } \\
\text { de outra, mas a gente conversava bastante e cada um cuidava de uma parte. }\end{array}$ \\
\hline Esposa Sócio 3 & Eu acho que era. \\
\hline Membros & Respostas com relação à sucessão e o que almejavam para o futuro \\
\hline Sócio 1 & $\begin{array}{l}\text { Nós fizemos a nossa divisão quando o meu pai era vivo e hoje eu estou tentando fazer a } \\
\text { nova divisão.... Nós somos três sócios e eu quero me dividir enquanto a gente tem saúde } \\
\text { e a gente tem certa dificuldade dentro da família e dentro da empresa .... muito compli- } \\
\text { cado, pra tu dividir os bens, pois um quer lá, o outro quer lá, o outro quer lá .... Então é } \\
\text { complicado.... No entanto posso dizer: "Eu sou majoritário dentro da empresa, todas as } \\
\text { decisões passam pela minha mão, eu tomo as decisões e a gente vai pegar e se dividir". }\end{array}$ \\
\hline Esposa Sócio 1 & $\begin{array}{l}\text { Como o Sócio } 1 \text { era mais velho ficou com mais percentual, pois trabalhou mais. Os outros } \\
\text { saíram para estudar e trabalharam menos. Daí o Sócio } 1 \text { teve que decidir quando à divisão } \\
\ldots . \text { Ele está tentando fazer assim novamente, mas .... Não sei se vai dar certo. Tomara } \\
\text { que dê! .... É que na verdade nenhum quer ceder, ninguém quer sair cedendo. Dessa } \\
\text { forma, para entrar em consenso está muito difícil. }\end{array}$ \\
\hline
\end{tabular}




\begin{tabular}{ll}
\hline Membros & \multicolumn{1}{c}{ Respostas com relação à forma de gerir a organização entre os irmãos } \\
\hline Sócio 2 & $\begin{array}{l}\text { Meu pai passou a empresa para o Celestino e daí cada um ficou com uma porcentagem da } \\
\text { empresa. Então já tinha um tipo de administração e esta só continuou .... Não nos pro- } \\
\text { gramamos para uma nova sucessão. A gente fazia reunão e tudo andava a mil maravi- } \\
\text { lhas .... Para uma nova sucessão dar certo cada um deveria dar uma ideia própria e ter } \\
\text { uma pessoa, um responsável que pudesse nos auxiliar sobre a maneira ideal de fazermos a } \\
\text { sucessão. }\end{array}$ \\
\hline Sócio 3 & $\begin{array}{l}\text { Na nossa época a sucessão foi feita do pai para os três sócios (filhos). No momento, a } \\
\text { ideia é separar a nossa sociedade para cada um seguir o seu caminho, pois geralmente } \\
\text { na terceira geração já é bastante dificultoso para gerir uma empresa familiar .... Alguns } \\
\text { resistem mais que os outros e começam a vir novas ideias, filhos, sobrinhos .... a terceira } \\
\text { geração começa a trabalhar na empresa e nisso começam a surgir os problemas. }\end{array}$ \\
\hline Esposa Sócio 3 & Nada a declarar.
\end{tabular}

Quanto às respostas com relação à forma de gerir a organização entre os irmãos, destaca-se que de todos os membros, apenas a Esposa do Sócio 3 acreditava haver uma forma convergente de gerir os negócios da família. Ao contrário, os três irmãos foram enfáticos em afirmar que possuem discordância na forma de gerir a empresa familiar conduzida por eles. Dois dos membros concordavam que existia uma semelhança na forma de gerir entre o Sócio 1 e o Sócio 3, sendo o Sócio 2 o mais diferente.

Esses achados sugerem que cada sócio pode enxergar a empresa de uma forma diferente, com seus próprios princípios e conceitos, de como é a melhor forma de gerenciar o negócio da família. Esse é um indicativo muito importante, visto que na empresa familiar as decisões são também carregadas de sentimentos (Kellermanns et al., 2014). Desse modo, compreende-se a necessidade de que mais dicussões e reuniões fossem realizadas de modo que as decisões tomadas entre os sócios tenham concenso e não causem conflito ou despertem a rivalidade.

Já quanto às respostas concedidas na entrevista, com relação à sucessão e ao que almejavam para o futuro da empresa, os membros afirmaram que não estavam preparados e que não haviam se planejado para uma nova sucessão. Compreende-se isso como um dos grandes problemas que ocasionaram a dissolução, além dos conflitos familiares latentes. Quando questionados, afirmaram a dificuldade e as complicações geradas pelo fato de que a empresa é familiar e, nesse caso, existem critérios afetivos ligados à organização, o que acaba por fazer que uns sócios resistam mais do que outros, e que ninguém ceda para que um consenso seja alcançado.

Esse resultado pode ser explicado por Scheffer (1995), pois a resistência e a falta de controle dificultam ainda mais o processo de sucessão em razão da disputa pela posse do controle do negócio entre os membros da família. Além disso, Kilduff et al. (2010) aduzem que as rivalidades geradas nesse contexto são subjetivas e desenvolvidas na mente dos membros da empresa familiar. 
Sem condições de concordarem entre si em como perpetuar a organização, os sócios em conjunto decidiram por diluir a sociedade e dividir os bens, apesar de afirmarem ser um processo penoso e demorado, de modo que, com a divisão, cada um possa tomar suas próprias decisões e com a parte do seu capital fazer o gerenciamento que achar conveniente. Para tanto, a dissolução dessa sociedade acaba por levar mais essa empresa à estatística das empresas familiares que encontram problemas ao chegarem na terceira geração, apesar da inegável importância que estas têm na forma política, social, cultural e econômica em diversos países do mundo (Estol \& Ferreira, 2006; Paiva \& Melo, 2008).

\subsection{PROBLEMAS FAMILIARES E RIVALIDADE}

Com relação aos problemas familiares e às rivalidades, tem-se diversos aspectos que demonstram que isso era uma realidade da empresa e que possivelmente contribuiu para a dissolução da sociedade. Assim, ao se questionar os membros da empresa familiar sobre quais eram os sentimentos percebidos nos momentos de dificuldades na empresa, obtiveramse as seguintes respostas, que estão expostas na Figura l:

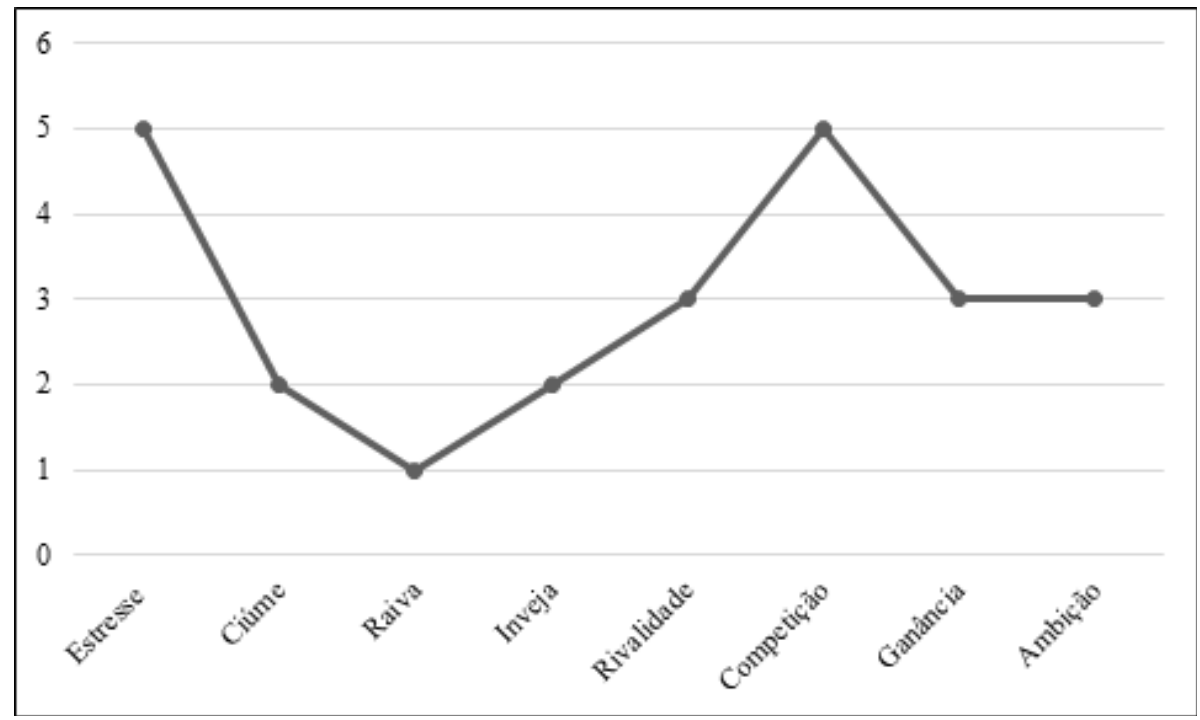

Figura 1. Sentimentos percebidos nos momentos de dificuldades.

A partir da Figura 1 é possível visualizar que o estresse e a competição apresentaram os maiores ápices nos momentos que em havia dificuldades dentro da empresa familiar. Esses sentimentos certamente acabavam atrapalhando a gestão, e, como exposto por Kilduff et al. (2010), no momento em que se coloca maior relevância na competição contra o outro agente, acaba existindo rivalidade. 
Isso se confirma a partir dos resultados, pois é possível ver que a rivalidade também foi apontada como um sentimento exalado quando a empresa passava por dificuldades. Assim, no momento em que o sentimento de competição está em alta aumenta o sentimento de rivalidade em relação aos demais membros da empresa. Friedman (1991) frisa que, nesses casos, quando a competição não for condizente com os objetivos, metas e valores da organização, tendo como foco os interesses particulares, haverá a redução da possibilidade de ganhos futuros. Kilduff et al. (2010) e Maccari et al. (2006) contribuem para essa discussão ao frisarem que quanto maior for a competição, maior será a rivalidade existente nessas empresas, fazendo com que os objetivos da empresa familiar sejam perdidos.

Outros dois sentimentos que foram apontados com mais frequência foram a ganância e a ambição. Para tanto, entende-se que para que a gestão seja bem-sucedida em uma empresa familiar, é preciso dar maior atenção a esses sentimentos, com vistas a controlálos de alguma forma, como a partir da própria inteligência emocional dos envolvidos. Os membros também foram questionados se consideraram que os sentimentos, emoção e paixão interferem de forma direta na tomada de decisões da empresa. Em relação a esse questionamento, um respondente $(20 \%)$ respondeu que não interfere, um respondente (20\%) marcou a opção de que interfere pouco, dois respondentes (40\%) responderam que interfere muito e um respondente (20\%) que interfere extremamente. A partir dessas respostas, entende-se que a maioria acredita que ao ter presente tais sentimentos, a gestão da organização pode acabar sendo comprometida.

Esse fato também pode resultar no não atingimento de metas e objetivos, o que foi apontado por $60 \%$ dos membros (três respondentes) e da mesma forma, emoções negativas como: medo, raiva e ciúmes podem interferir de forma direta no desempenho da empresa, para $60 \%$ dos respondentes, sendo que os demais consideram que essas emoções interferem pouco $(20 \%)$ e nem pouco, nem muito $(20 \%)$, o que condiz com as respostas anteriores.

Diante do exposto, percebe-se que os sentimentos presentes nessa empresa são mais notáveis e possuem relação direta com o desempenho da organização, o que exige que sejam tomadas providências e medidas preventivas para minimizar os impactos que causam, ou até mesmo buscar formas para eliminá-los. Até porque esses sentimentos negativos acabam por tornar os próprios membros como rivais uns dos outros, apresentando um espírito competitivo, conforme já exposto anteriormente.

Nesse sentido, é importante levar em consideração a questão relacionada ao fato de se considerarem mais emocionais ou racionais, em que $40 \%$ dos respondentes se consideraram extremamente emocionais, $20 \%$ emocionais, $20 \%$ nem emocionais e nem racionais e os outros $20 \%$ racionais. Isso demonstra que os sentimentos interferem muito na empresa analisada, o que pode causar mágoas, e com o passar dos anos, quando essas mágoas, insatisfações e decepções forem aumentando e acumulando, como raiva, rivalidade, competição e ganância, poderá haver consequências drásticas para a gestão. 
Esse fato aconteceu com a empresa em que se realizou o estudo de caso e, exposto de forma resumida na Tabela 3, iniciando com o ponto de vista dos irmãos sócios, seguido da visão das esposas apresentada na Tabela 3:

\section{Tabela 3}

Principais situações que geraram discordâncias e conflitos no ambiente de trabalho sob ponto de vista dos irmãos sócios

\begin{tabular}{ll}
\hline Membros & \multicolumn{1}{c}{ Resposta da entrevista } \\
\hline & Quando chega na quarta geração, se tem os filhos envolvidos, estes vão casando e envolvendo \\
outras pessoas, integrando a família, o que acaba complicando ainda mais a gestão. Eu sem- \\
pre fiz a minha parte. Chegou um momento que houve um conflito com o Sócio 2, pois este se \\
separou e começou a relaxar com a fábrica, chegando a um ponto em que tivemos que pa- \\
rar o nosso negócio. Nós tínhamos uma filha que tinha interesse de continuar na empresa. \\
Entretanto, um dos sócios começou a implicar, pois ela quis melhorar os processos da empresa \\
e ele não admitia que uma pessoa mais jovem pudesse fazer melhor. \\
Uma pessoa é diferente da outra e por isso não deu mais certo. Cada empresa tem épocas \\
boas e ruins. Nas épocas boas, quando sobra dinheiro é só alegria, todo mundo bate palmas. \\
Já quando vem uma crise, acaba resultando em um descontentamento. Há a condenação \\
de uma pessoa que sempre estava pensando no bem comum, e isso gera um mal-estar na \\
família. Daí não se acredita mais na empresa. Outro descontentamento meu é porque sonhá- \\
vamos em comprar uma fazenda para a gente ter uma aposentadoria um dia. Assim, traba- \\
lhamos muito, viramos noites trabalhando até comprar essa fazenda, que era para ser um bem \\
em comum entre os sócios. Um dos irmãos ficou responsável para atender essa fazenda e nos \\
apresentar seus resultados, no entanto, passaram-se 16 anos e não tivemos nenhuma prestação \\
de contas de lá. Então, foi como se fosse uma propriedade particular. O que planejamos para \\
ser nosso acabou por virar uma coisa ruim, gerando um clima ruim entre nós três.
\end{tabular}

Conforme exposto no Tabela 3, percebe-se que as principais situações que geraram discordâncias e conflitos no ambiente de trabalho sob o ponto de vista dos irmãos sócios foi conforme a opinião do Sócio 1 , de que a partir da quarta geração fica tudo ainda mais complicado. Além disso, a questão da separação de um dos irmãos acabou atrapalhando a participação deste nos negócios da família, bem como toda a gestão. Outra questão apontada é com relação ao interesse de continuação da empresa por parte da sua filha, mas que não foi muito aceita pelos demais.

Contudo, o fato de não ter sido aceita pode ser explicado por Tillmann e Grzybovski (2005) por não haver preparação suficiente, qualificação e conhecimentos necessários para dar continuidade ao negócio familiar. Mas o que pode ter ocorrido também é a falta de confiança ou simplesmente por querer contrariar aquele irmão. É por isso que Reyna e Encalada (2016) destacam que a minoria das empresas familiares consegue passar a gestão aos descendentes sem dificuldades, o que aumenta a complexidade do processo. 
Para Andrade et al. (2003) à medida que dois ou mais irmãos acabam discordando da política organizacional e dos papéis de cada um no processo, ocorrem as rivalidades. Isso é intensificado quando os membros da família trazem consigo diferentes ideais, intensificando o conflito já existente e tornando ainda mais complexo o processo sucessório.

O Sócio 2 relatou que o que mais gerou discordância foi o fato de um irmão ser diferente dos demais, e que a alegria era um sentimento comum, mas somente quando havia dinheiro. Ainda, que os demais membros não valorizavam as ideias e não percebiam o desejo de ajudar por parte desse membro. Comentou também, sobre um investimento que era o sonho dos irmãos, de comprar uma fazenda, o que se tornou algo que acabou gerando muita rivalidade entre eles.

Diante do exposto pelos irmãos, tendo em vista que se expuseram apenas os pontos mais relevantes, destaca-se que a questão do descontentamento na empresa e em toda gestão familiar foi sentida em diversos e diferentes momentos pelos sócios. Cada um apresentava alguns pontos, o que nem sempre foi o que o outro irmão apresentava. Assim, percebe-se que as visões deles com relação à família, à gestão e ao futuro da empresa eram muito distantes e isso foi distanciando cada vez mais a família com o passar dos anos, quando os filhos já iam crescendo, ajudando ou querendo ajudar na gestão da empresa.

A seguir, expõe-se o ponto de vista das esposas sobre os conflitos e as discordâncias que mais assolavam a organização.

Tabela 4

Principais situações que geraram discordâncias e conflitos no ambiente de trabalho sob ponto de vista das esposas

\begin{tabular}{|c|c|}
\hline Membros & Resposta da entrevista \\
\hline $\begin{array}{l}\text { Esposa } \\
\text { Sócio } 1\end{array}$ & $\begin{array}{l}\text { Eu tentava falar, sempre falar: "Olha, vamos entrar em um acordo, não vamos discutir, va- } \\
\text { mos conversar que é melhor". Sempre tentava interferir quando eles estavam discutindo. Nós } \\
\text { ficávamos de lado, mas quando víamos que o clima estava ficando tenso, interferia: "Não, va- } \\
\text { mos tentar por bem, vamos tentar achar alguma solução". No nosso caso, uma das esposas } \\
\text { dos sócios trabalhava e as outras não: "Por que que eu tenho que trabalhar e elas não?" Uma } \\
\text { das outras justificava dizendo: "Eu só vou trabalhar quando for só nosso, daí eu vou ajudar". Por } \\
\text { isso nenhuma das esposas se motivava a ajudar na administração .... Então vamos separar } \\
\text { a empresa para evitar maiores desentendimentos. São difíceis as relações porque sempre tem } \\
\text { alguém que fala: "Você tem que me obedecer porque você trabalha aqui na empresa". Mas } \\
\text { eu acho que não é por aí. }\end{array}$ \\
\hline $\begin{array}{l}\text { Esposa } \\
\text { Sócio } 3\end{array}$ & $\begin{array}{l}\text { Ninguém tinha salário definido e cada um retirava o valor de acordo com a sua necessida- } \\
\text { de. Durante um tempo isso não gerou conflito, mas eu acho que muitas vezes causa descon- } \\
\text { tentamento, porque às vezes você gostaria de melhorar a sua casa ou carro, ajudar seus filhos. } \\
\text {... Isso eu acho que deveria ter sido um pouco diferente. }\end{array}$ \\
\hline
\end{tabular}

Percebe-se que as esposas apresentaram descontentamentos e diferentes situações sobre a empresa familiar. A Esposa do Sócio 1 não concordava com o fato que as demais esposas não precisassem trabalhar na empresa, o que também não estava a motivando para continuar na administração. Além disso, não gostava que mandassem nela e a tratassem 
como uma mera funcionária, tendo em vista que fazia parte da família. Ainda, destacou que sempre tentava ajudar quando havia conflitos, acalmando os membros, ressaltando o quão importante seria a conversa, as reuniões, buscando soluções.

Já a Esposa do Sócio 3 se voltou mais para a questão do salário, que não concordava que cada um tirava do caixa da empresa a quantia que bem entendesse, o que gerava descontentamento por parte dos demais e que também gostariam de evoluir financeiramente.

Assim, é visível que a Esposa do Sócio 1 tinha maiores preocupações com toda a organização, preocupações com a continuidade desta e buscava amenizar os conflitos que ocorriam na empresa eventualmente. Além disso, sentia-se injustiçada por ser a única que trabalhava assiduamente na empresa, pois por mais que a Esposa do Sócio 3 fizesse parte da administração da empresa, o entendimento é que trabalhava em determinados momentos somente. Nesse sentido, nota-se que a Esposa do Sócio 3 tinha como maior preocupação o financeiro, o que pode ter acentuado ainda mais a rivalidade entre as esposas, bem como entre os irmãos, justamente em decorrência do envolvimento das esposas na gestão.

Para tanto, é possível notar que ambas as esposas pensavam de formas bem distintas, uma mais preoucupada com o fato de buscar evoluir financeiramente, já a outra, mais preocupada em seguir com o empreendimento e convocar reuniões para identificar erros. O resultado corrobora os achados de Stocker e Youngblade (1999), que verificaram que o conflito conjugal eleva ainda mais os conflitos já existentes entre os irmãos e a rivalidade presente. Diante disso, é preciso tomar cuidado, pois normalmente isso ocorre por conta de os interesses pessoais falarem mais alto, sendo esse um problema que dificulta a sobrevivência de qualquer empresa (Moreira, 2006), nesse caso, de uma empresa familiar. Na Tabela 5 foram pontuadas algumas possíveis soluções para essas discordâncias e conflitos no ambiente de trabalho apresentados pelos membros:

Tabela 5

Possíveis soluções apontadas para as discordâncias e os conflitos no ambiente de trabalho

\begin{tabular}{ll}
\hline \multicolumn{1}{c}{ Membros } & \multicolumn{1}{c}{ Resposta da entrevista } \\
\hline Esposa Sócio 1 & $\begin{array}{l}\text { A melhor alternativa para manter a empresa seria contratar pessoas que não fossem da } \\
\text { família para gerir. }\end{array}$ \\
\hline Sócio 2 & $\begin{array}{l}\text { Uma alternativa que eu apontaria para salvar a empresa seria cada um dos sócios arru- } \\
\text { mar um sucessor e passarmos as coordenadas para os nossos filhos. }\end{array}$ \\
\hline Esposa Sócio 3 & $\begin{array}{l}\text { Como solução, todos os envolvidos na gestão da empresa familiar deveriam saber separar } \\
\text { os assuntos. }\end{array}$ \\
\hline
\end{tabular}

Ressalta-se que nem todos foram os membros que apontaram soluções, entretanto, destaca-se as que ficaram em evidência. $O$ que chama a atenção é que apenas as duas esposas e o Sócio 2 apresentaram possíveis saídas para os problemas da gestão familiar. As alternativas vislumbradas foram a de se contratarem pessoas que não tivessem vínculo familiar para gerir; cada sócio colocar na empresa um sucessor; e separar os assuntos da 
tríade família, propriedade e negócios, o que pode ser explicado em razão do fato de esse casal (Sócio 3 e Esposa Sócio 3) ter exposto em um relato da entrevista por parte do Sócio 3 que o casal não conseguia separar os assuntos.

Tendo em vista o exposto, entende-se que realmente são soluções que poderiam ajudar e mudar o cenário da empresa e evitar a dissolução, desde que tivessem sido realizadas antes de os conflitos se tornarem mais acalorados, refletindo em rivalidades entre irmãos, entre os cônjuges e entre todos os membros.

Por mais que haja problemas e conflitos, os irmãos, que são o pilar da empresa familiar, precisam saber lidar ou aprender a lidar com o crescimento e a complexidade dos processos institucionais, conforme aponta Dana e Smyrnios (2010). Em muitos dos casos, quando os conflitos forem diretamente entre os sócios, o que também ocorreu neste estudo de caso, Pieper (2010) frisa que isso pode indicar que os proprietários realmente querem ficar juntos.

$\mathrm{Na}$ Tabela 6 são apresentadas as respostas sobre a interferência dos problemas familiares na empresa, a forma com que são tratados os assuntos do trabalho em casa, com a família e a inteligência emocional dos demais membros.

Tabela 6

Interferência dos problemas familiares na empresa versus Tratar sobre assuntos do trabalho em casa e inteligência emocional

\begin{tabular}{llll}
\hline \multicolumn{1}{c}{ Membros } & $\begin{array}{c}\text { Interferência dos problemas } \\
\text { familiares na empresa }\end{array}$ & $\begin{array}{c}\text { Em casa: costumam tratar } \\
\text { assuntos da empresa }\end{array}$ & $\begin{array}{c}\text { Os demais membros pos- } \\
\text { suem inteligência emocional }\end{array}$ \\
\hline Sócio 1 & IM & MV & Não \\
\hline Esposa Sócio 1 & IM & MV & Não \\
\hline Sócio 2 & IC & S & Não \\
\hline Sócio 3 & IP & PV & Sim \\
\hline Esposa Sócio 3 & IM & PV & Sim \\
\hline
\end{tabular}

Nota. Interfere Pouco (IP); Interfere Muito (IM); Interfere Completamente (IC).

Muitas Vezes (MV); Poucas Vezes (PV); Sempre (S).

A partir do exposto na Tabela 6 é possível perceber que em relação à interferência dos problemas familiares na empresa $60 \%$ das respostas foram que Interfere Muito (IM), $20 \%$ (um respondente) que Interfere Completamente (IC) e o outro, representando os demais $20 \%$, que Interfere Pouco (IP). Assim, entende-se que há uma controvérsia quanto à resposta do Sócio 3, visto que na entrevista, diferente do que respondeu a partir dessa pergunta, infere que: "Quando surge algum problema, você acaba muitas vezes levando isso para dentro de casa, ficando agressivo, nervoso e descontando geralmente todos estes problemas na esposa ou filho, mesmo sempre tentando separar os assuntos empresariais dos familiares" (Sócio 3, informação verbal). 
Para tanto, ao triangular essas informações, fica evidente que ele se contradiz, demonstrando que, muitas vezes, os membros de uma empresa familiar tentam ocultar informações no que diz respeito à sua relação familiar, tentando evidenciar para a sociedade que estão tendo uma relação boa como empresa e família. Entretanto, como se sabe e a própria literatura indica, esse é um problema recorrente nesse tipo de organização e que prejudica a gestão, seja no curto seja no longo prazo, o que vai depender muito das pessoas que fazem parte desse ambiente terem inteligência emocional para conseguir superar determinadas situações. Contudo, sentimentos, emoções e rivalidades vão acumulando ao longo do tempo e, em determinado momento, isso aflorará, podendo ser tarde para voltar atrás e tentar mudar o contexto familiar, bem como o empresarial.

Além disso, esse mesmo membro (Sócio 3 ) e sua esposa destacaram que os demais membros possuem inteligência emocional, o que também se torna contraditório com suas respostas, pois se os problemas fossem todos resolvidos dentro da própria organização, com inteligência emocional, não seria preciso levar esses problemas para fora da empresa, ou seja, para dentro de casa.

Vale destacar, ainda, que todos responderam que costumam tratar sobre assuntos da empresa em casa, o que os diferencia é que o Sócio 1 e sua esposa responderam que muitas vezes estão imersos e não conseguem se desligar da empresa, tendo em vista que ambos trabalham nela, o que também pode explicar tal fato. Novamente o Sócio 3 e sua esposa apresentam uma resposta distorcida com a informação apresentada durante a entrevista, ao responderem que interfere pouco. Já o Sócio 2 destacou que interfere sempre. Esse é um fator que pode abalar estruturalmente qualquer família, pois há uma dificuldade muito grande em separar os negócios familiares, da própria família.

Para tanto, percebe-se que a tríade da empresa familiar em análise não está bem estruturada, visto que os membros não conseguem separar a família do negócio/empresa, sendo essa tríade normalmente a responsável pelo ciclo de vida da organização (Andrade et al., 2004). Essas fragilidades também são um indicativo de como a empresa apresenta dificuldades para a sucessão. $O$ que acontece nesses casos e que pode ser explicado por Gómez-Mejía et al. (2007) é que a empresa familiar é permeada por um antagonismo de interesses e ações, os sócios não estarem dispostos a assumir riscos, e, assim, acabarem colocando todo o desempenho da organização em risco.

\subsection{PROBLEMAS ENTRE IRMÃOS E RESPECTIVOS CÔNJUGES}

Quando os conflitos entram para o âmbito familiar, certamente as dificuldades das empresas são agravadas por questões como envolvimento afetivo transgeracional, falta de conhecimento de gestão, nepotismo e falta de limites a alguns funcionários, sendo que 
estas interferem nas escolhas e interesses da organização. Isso acontece muito em empresas familiares, nas quais as novas gerações, que incluem filhos e cônjuges, passam a integrar as rotinas da administração e o controle da empresa familiar.

Como discutida na literatura a existência desses conflitos por Friedman (1991), Moreira (2006), Pieper (2010), Webb et al. (2010), Gómez-Betancourt et al. (2013) e Reyna e Encalada (2016), foram interrogados os membros da empresa familiar, tanto por meio do questionário quanto da entrevista com relação aos conflitos e à tensão gerados no ambiente de trabalho em decorrência de possíveis brigas entre os casais. Os resultados são apresentados na Tabela 7, que pode ser observada a seguir:

Tabela 7

Respostas com relação às brigas entre casais, se geraram algum conflito e tensão no ambiente de trabalho

\begin{tabular}{|c|c|}
\hline Membros & Resposta da entrevista \\
\hline Sócio 1 & $\begin{array}{l}\text { Interferiu! O meu irmão se separou e tem três filhas e ele pegou, simplesmente abandonou a } \\
\text { empresa neste momento. }\end{array}$ \\
\hline $\begin{array}{l}\text { Esposa } \\
\text { Sócio } 1\end{array}$ & $\begin{array}{l}\text { Interferiu, na questão de: "Aí você gasta mais, você gasta menos". Então sempre tem assim um } \\
\text { que economiza, mas o outro já extrapola né, então.... Sempre tinha bastante discussão sobre } \\
\text { isso. Além de que, às vezes, não poder dar a sua ideia, é "porque você é a mulher dele" então } \\
\text { você não pode. Você tem que obedecer o que nós mandar, eu acho que daí ficava aquele senti- } \\
\text { mento né ... Mas como é uma família, você quer preservar a família. Porque a família é o mais } \\
\text { importante. Viver em harmonia com a família, senão mais tarde você não puder nem visitar teu } \\
\text { cunhado e cunhada por conta de intriga da empresa?! }\end{array}$ \\
\hline Sócio 2 & $\begin{array}{l}\text { Com certeza interferia. Eu acho que se o casal não vai bem em casa reflete na empresa, pois } \\
\text { o marido faz parte da empresa e a mulher não tem nada a ver com isso. Não é sócia né?! As } \\
\text { mulheres não são sócias da empresa. Mas na tensão em casa, o marido segue mais o que a mu- } \\
\text { lher fala. Não é o meu caso, eu sou independente, a mulher não interfere em nada nas minhas } \\
\text { escolhas. Lá na empresa eu que mando. Mas têm situações que a mulher que toma decisão e o } \\
\text { marido é mandado pela mulher, é complicado. Você tem um sócio, mas ao mesmo tempo ele né, } \\
\text { não tem as suas decisões próprias dele pra tomar decisão, ele é mandado pela mulher. A pessoa } \\
\text { não age por si próprio, né?! Tudo vem de casa. }\end{array}$ \\
\hline Sócio 3 & Não. \\
\hline $\begin{array}{l}\text { Esposa } \\
\text { Sócio } 3\end{array}$ & $\begin{array}{l}\text { Eu acho que não, porque no trabalho era bem separado, assim, cada um cuidava da sua fun- } \\
\text { ção, não ficavam muito juntos os casais. A Esposa do Sócio } 1 \text { trabalhava na empresa, eu quase } \\
\text { não trabalhei junto, daí a ex-mulher do Sócio } 2 \text { também não. Então, era bem tranquilo. Apesar } \\
\text { de que, às vezes, em casa né, o estresse quando o marido aparecia ... . mas faz parte. }\end{array}$ \\
\hline
\end{tabular}

De acordo com o observado na Tabela 7, três dos membros concordavam com a interferência dos problemas dos cônjuges na administração da empresa, sendo eles um casal, o Sócio 1 e respectiva Esposa, e o Sócio 2.

Observa-se que na entrevista o Sócio 3 e sua respectiva Esposa não tiveram a mesma percepção como os outros membros, afirmaram que os problemas conjugais entre os membros da organização não afetaram os processos da empresa, sendo uma constatação importante. As respostas convergentes do casal podem demonstrar que ambos possuem uma forma diferente de ver os demais sócios, afirmando desconhecer determinadas informações, ou não enxergando com os mesmos olhos os ocorridos na organização. No entanto, por se tratar de uma empresa familiar, cada informação é de suma importância para seu desenvolvimento sadio. 
Ressalta-se que por muitas vezes os conflitos da organização podem ser ocasionados por desentendimentos e divergências de ideias sobre questões particulares, bem como por aspectos relacionados ao negócio da família, ocorridos no seio familiar, podendo variar conforme os interesses de cada casal envolvido na gestão (Stocker \& Youngblade, 1999; Reid et al., 1999).

Além disso, a partir do momento em que os demais membros conseguem vislumbrar uma relação de interesse em conflito com as políticas da organização, existente entre os cônjuges ou não, eles precisam tomar posicionamentos com vistas à proteção dos interesses da organização, ao passo que evitem que desentendimentos atrapalhem o desempenho da empresa familiar. Os problemas decorrentes da divergência entre entendimentos é basicamente o que torna sócios em rivais, pode ser sutil a relação existente especialmente por se tratarem de irmãos que por anos podem disputar atenção ou mesmo poderes no ambiente familiar e empresarial.

Diante de todo o contexto apresentado anteriormente, a Figura 2 apresenta uma trajetória da empresa familiar em análise, de forma resumida, com os acontecimentos que mais marcaram e que a levaram à sua situação atual.

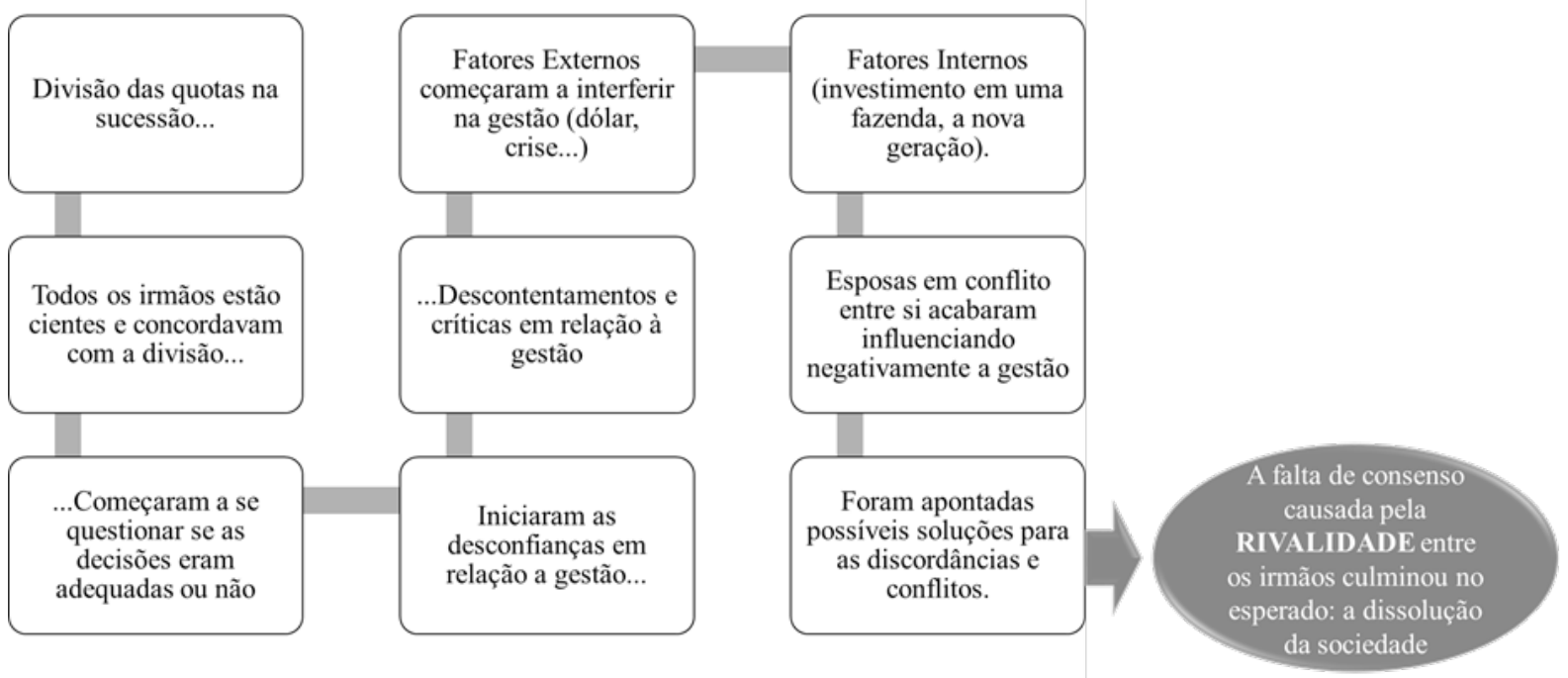

Figura 2. Trajetória da empresa familiar e sua relação com a rivalidade.

A partir da análise da Figura 2 é possível destacar pontos em que a temática da rivalidade se sobressai desde a constituição da empresa até a sua dissolução. A divisão de quotas foi o marco inicial que eclodiu na rivalidade entre os irmãos (sócios), visto que a divergência entre as quotas de capital já os tornava diferentes, dando mais poder a um do que aos demais, sendo somente contestado após alguns anos da gestão conjunta.

As divergências surgiram especialmente a partir do momento em que fatores externos passaram a influenciar os resultados financeiros da organização, levantando dúvidas e 
desconfianças dos demais sócios com relação à gestão. Essa desconfiança foi também em decorrência dos fatores internos, como outros investimentos com os resultados financeiros da empresa, possível sucessão concentrada em apenas uma família, bem como participação das esposas na gestão, o que tornou os problemas ainda maiores e mais visíveis. Por mais que houvesse tentativas para resolver alguns desses problemas internos que afetavam diretamente a gestão, as soluções não foram consensuais e resultaram na dissolução da sociedade.

Este estudo de caso converge com outros estudos anteriores como os de GómezMejía et al. (2007), Astrachan e Jaśkiewicz (2008), Zellweger e Astrachan (2008), GómezBetancourt et al. (2013) e Kellermanns et al. (2014) sobre a necessidade de gerenciamento de emoções dentro de empresas familiares e que, quando isso não ocorre, os resultados podem ser significativamente negativos. Além disso, este estudo discute a rivalidade, que pode ser um fator intrínseco dentro da relação entre irmãos, em que é preciso saber gerir as emoções e separar os negócios pessoais dos profissionais, mas sempre levando em consideração a tríade negócio, família e propriedade.

\section{CONCLUSÃO}

A partir do objetivo de descrever os impactos causados pela rivalidade entre irmãos na gestão de empresas familiares, realizou-se uma pesquisa descritiva por meio de estudo de caso, com abordagem qualitativa. Para a realização deste estudo foram entrevistados membros de uma empresa familiar que previamente já haviam respondido um questionário acerca das suas opiniões sobre o funcionamento da gestão e conflitos existentes. Além disso, foram disponibilizados pelos próprios sócios os dados secundários utilizados na análise documental utilizados na triangulação dos dados.

A partir dos resultados percebe-se que a rivalidade já esteve presente na empresa familiar analisada desde seu processo sucessório em razão da diferença das quotas referentes à sociedade. Por mais que isso não tenha sido apontado desde o início, afirmaram por meio da entrevista que havia um consenso sobre essa divisão, contudo, ao passar dos anos, esse problema foi trazido à tona, demonstrando que começava a aflorar na empresa a rivalidade entre os irmãos e todos os membros.

Por conta disso, começaram os questionamentos e a desconfiança sobre a gestão, e fatores externos bem como internos começaram a influenciar esse problema. Além disso, outro fato observado que foi determinante para o aumento da rivalidade foi a presença das esposas na gestão da empresa. Por mais que os membros soubessem que não deveriam misturar os negócios da família com os da empresa, bem como que deveriam tomar determinadas atitudes para mudar e reverter a situação antes que fosse tarde, como, por 
exemplo, o processo sucessório, estes não o fizeram a tempo de evitar a dissolução da empresa familiar.

Diante do exposto, conclui-se que a rivalidade impacta de forma negativa os resultados das organizações familiares, especialmente nos casos que envolvem outras pessoas da família no negócio e que não conseguem separar a tríade negócio, família e propriedade. A gestão é influenciada, ainda, pela falta de inteligência emocional dos membros, assim, a organização pode sofrer diversos prejuízos, incluindo em casos extremos a dissolução.

Tendo em vista os resultados encontrados, denota-se que, de modo geral, os conflitos familiares, apesar de existentes por razões naturais entre irmãos, acabam por aguçar a rivalidade entre sócios, prejudicando o bom relacionamento na gestão de empresas familiares, ocasionando em casos extremos, como o estudado, que a empresa não tenha condições de evitar consequências, o que leva à dissolução.

Sabendo que empresas familiares têm problemas sucessórios e que isso já é algo histórico e recorrente na literatura, conforme já apontado por Scheffer (1995) e Morris et al. (1996) em seus estudos sobre processos sucessórios, muitas vezes por se tratarem de famílias e a gestão passar de pais para filhos, estes acabam sendo treinados de acordo com os costumes e hábitos já institucionalizados dentro da própria empresa, visto que, por vezes, nem curso superior possuem.

Entende-se como primordial para o triunfo da empresa familiar o treinamento das habilidades para lidar com as pessoas, de modo que além de diferenças individuais dos membros de sua família, outras surgirão, como os cônjuges e posteriormente os filhos, e cada qual possui uma interpretação sobre as melhores condições para que uma empresa permaneça em mercado. Para tanto, seria importante que os órgãos públicos e governamentais oferecessem algum tipo de curso e treinamentos para esse tipo de empresa, tendo em vista que as empresas familiares são representativas para as economias nacional e internacional.

O estudo contribui com a teoria por investigar uma lacuna de pesquisa que se refere às rivalidades, e que, até então têm sido ignoradas, principalmente nos estudos do contexto nacional e, por mais que de certa forma foram abordados nos artigos, não se localizou nenhum estudo que tenha dado a devida atenção a esse aspecto. Entretanto, essa temática assume relevância e é responsável por grande parte dos conflitos que impossibilitam as empresas familiares a continuarem seus negócios com êxito.

Além disso, este estudo contribui com uma nova perspectiva de pesquisa, por meio da pesquisa qualitativa e estudo de caso, que permitem captar elementos que não são possíveis a partir de dados secundários. Há também a falta de pesquisas qualitativas que captem essas informações e propiciem o devido aprofundamento, relacionando com aspectos comportamentais, em especial, relacionados às emoções, o que impacta diretamente a gestão, sucessão e continuidade da empresa. 
Como limitação deste estudo, tem-se o fato de ser um estudo de caso, e, por conta disso, os resultados não podem ser generalizados para as demais empresas familiares. Assim, recomendam-se novos estudos de caso com empresas familiares ou estudos multicasos. Isso por se tratar de um tipo de organização com diversas particularidades. Dessa forma, os resultados deste estudo poderão ser utilizados para fins de comparabilidade dos resultados.

\section{REFERÊNCIAS}

Andrade, D. M., Grzybovski, D., \& de Lima, J. B. (2004). Aplicabilidade do "modelo dos três círculos" em empresas familiares brasileiras: Um estudo de caso. Revista Eletrônica de Administração, 11(5), 1-25.

Andrade, D. M., Rezende, C. F., \& Rezende, D. (2003). Gestão e sucessão em empresas familiares: Um estudo de caso no ramo de laticínios. Anais do Encontro de estudos sobre empreendedorismo e gestão de pequenas empresas - EGEPE, Brasília, DF, 3.

Astrachan, J. H., \& Jaśkiewicz, P. (2008). Emotional returns and emotional costs in privately held family businesses: Advancing traditional business valuation. Family Business Review, 21(2), 139-149.

Atalay, C. G., \& Özler, D. E. (2013). A Research to Determine the Relationship between Organizational Justice and Psychological Ownership among Non-family Employees in a Family Business. Procedia-Social and Behavioral Sciences, 99, 247-256.

Athanassiou, N., Crittenden, W. F., Kelly, L. M., \& Marquez, P. (2002). Founder centrality effects on the Mexican family firm's top management group: Firm culture, strategic vision and goals, and firm performance. Journal of World Business, 37(2), 139-150.

Beckhard, R., \& Dyer, W. G. (1983). Managing continuity in the family-owned business. Organizational Dynamics, 12(1), 5-12.

Dana, L. E., \& Smyrnios, K. X. (2010). Family business best practices: Where from and where to? Journal of Family Business Strategy, 1(1), 40-53.

Estol, K. M. F., \& Ferreira, M. C. (2006). O processo sucessório e a cultura organizacional em uma empresa familiar brasileira. Revista de Administração Contemporânea, 10(4), 93-110.

Friedman, S. D. (1991). Sibling relationships and intergenerational succession in family firms. Family Business Review, 4(1), 3-20. 
Gómez-Betancourt, G., Ramírez, J. B. B., \& Vergara, M. P. L. (2013). Factores que inFluyen en la inteligencia emocional de los miembros de una empresa Familiar. Entramado, 9(1), 12-25.

Gómez-Mejía, L. R., Cruz, C., Berrone, P., \& Castro, J. (2011). The bind that ties: Socioemotional wealth preservation in family firms. The academy of management annals, 5(1), 653-707.

Gómez-Mejía, L. R., Haynes, K. T., Núñez-Nickel, M., Jacobson, K. J., \& Moyano-Fuentes, J. (2007). Socioemotional wealth and business risks in family-controlled firms: Evidence from Spanish olive oil mills. Administrative science quarterly, 52(1), 106-137.

Grote, J. (2003). Conflicting generations: A new theory of family business rivalry. Family Business Review, 16(2), 113-124.

Kellermanns, F. W., Dibrell, C., \& Cruz, C. (2014). The role and impact of emotions in family business strategy: New approaches and paradigms. Journal of Family Business Strategy, $5(3), 277-279$.

Kilduff, G. J., Elfenbein, H. A., \& Staw, B. M. (2010). The psychology of rivalry: A relationally dependent analysis of competition. Academy of Management Journal, 53(5), 943-969.

Labaki, R., Michael-Tsabari, N., \& Zachary, R. K. (2013). Emotional dimensions within the family business: Towards a conceptualization. Retrieved from https://coller.tau.ac.il/sites/ nihul.tau.ac.il/files/media_server/Recanati/management/strauss/publications/Labaki\%20 et\%20al\%20Chapter\%2031\%20-.pdf

Levinson, H. (1971). Conflicts that plague family businesses. Harvard Business Review, 49(2), 90-98.

Levinson, H. (1983). Consulting with family businesses: What to look for, what to look out for. Organizational Dynamics, 12(1), 71-80.

Lindow, C. M., Stubner, S., \& Wulf, T. (2010). Strategic fit within family firms: The role of family influence and the effect on performance. Journal of Family Business Strategy, 1(3), 167-178.

Lodi, J. B. (1986). A empresa familiar. São Paulo: Pioneira.

Maccari, E. A., Campanário, M. D. A., Almeida, M. I. R. D., \& Martins, A. (2006). Empresa familiar e as dificuldades enfrentadas pelos membros da $3^{a}$ geração. Anais do Encontro da Associação Nacional de Pós-graduação e Pesquisa em Administração, Salvador, 30. 
Martins, G. A. (2006). Estudo de caso: Uma estratégia de pesquisa. São Paulo: Atlas.

Massis, A., \& Kotlar, J. (2014). The case study method in family business research: Guidelines for qualitative scholarship. Journal of Family Business Strategy, 5(1), 15-29.

Moreira, A. L., Jr. (2006). Estratégias de governança na empresa familiar: Modelo para redução de conflitos familiares e perpetuação da empresa (Tese de doutorado). Universidade de São Paulo, São Paulo.

Morgan, T. J., \& Gómez-Mejía, L. R. (2014). Hooked on a feeling: The affective component of socioemotional wealth in family firms. Journal of Family Business Strategy, 5(3), 280-288.

Morris, M. H., Williams, R. W., \& Nel, D. (1996). Factors influencing family business succession. International Journal of Entrepreneurial Behavior \& Research, 2(3), 68-81.

Nordqvist, M., \& Melin, L. (2010). The promise of the strategy as practice perspective for family business strategy research. Journal of Family Business Strategy, 1(1), 15-25.

Paiva, K. C. M., \& Melo, M. C. D. O. L. (2008). Produção científica brasileira sobre empresa familiar - um metaestudo de artigos publicados em anais de eventos da ANPAD no período de 1997-2007. Revista de Administração Mackenzie, 9(6), 148-173.

Pieper, T. M. (2010). Non solus: Toward a psychology of family business. Journal of Family Business Strategy, 1(1), 26-39.

Reid, R., Dunn, B., Cromie, S., \& Adams, J. (1999). Family orientation in family firms: A model and some empirical evidence. Journal of Small Business and Enterprise Development, $6(1), 55-67$.

Reyna, J. M. S. M., \& Encalada, J. A. D. (2016). Sucesión y su relación con endeudamiento y desempeño en empresas familiares. Contaduría y administración, 61(1), 41-57.

Scheffer, A. B. B. (1995). Fatores dificultantes e facilitadores ao processo de sucessão familiar. Revista de administração, 30(3).

Sharma, P., Chrisman, J. J., \& Chua, J. H. (1997). Strategic management of the family business: Past research and future challenges. Family Business Review, 10(1), 1-35.

Stocker, C. M., \& Youngblade, L. (1999). Marital conflict and parental hostility: Links with children's sibling and peer relationships. Journal of Family Psychology, 13(4), 598. 
Tillmann, C., \& Grzybovski, D. (2005). Sucessão de dirigentes na empresa familiar: Estratégias observadas na família empresária. Organizações \& Sociedade, 12(32), 45-61.

Van den Heuvel, J., Goel, S., Gils, A. V., \& Voordeckers, W. (2007). Family businesses as emotional arenas. The influence of family CEO's empathy and external monitoring on the importance of family goals. Retrieved from https://www.researchgate.net/publication/30499345_Family_businesses_as_emotional_arenasThe_influence_of_family_ CEO\%27s_empathy_and_external_monitoring_on_the_importance_of_family_goals

Webb, J. W., Ketchen, D., Jr., \& Ireland, R. D. (2010). Strategic entrepreneurship within family-controlled firms: Opportunities and challenges. Journal of family business strategy, $1(2), 67-77$.

Zellweger, T. M., \& Astrachan, J. H. (2008). On the emotional value of owning a firm. Family Business Review, 21(4), 347-363. 


\section{APÊNDICE - Entrevista}

Perfil da Empresa (somente para o membro com a maior quota)

Qual o ano de constituição da empresa?

Quem foi o fundador de empresa (pai/mãe, avô/avó)?

Qual a forma jurídica da empresa?

Qual o setor de atividade da empresa?

N. de colaboradores da empresa:

Faturamento médio mensal:

Quantos sócios fazem parte da empresa?

Existem diferenças nas quotas de cada membro da família?

Quem são esses sócios (cônjuge, pais, filhos, outros familiares, empresários não familiares)?

Em que geração a empresa se encontra?

Todos os sócios trabalhavam na empresa? Caso sim, ocupavam os mesmos cargos? Caso não, por qual motivo?

\section{Sobre o Cargo de Administrador}

A opção de entrar na empresa foi própria ou influenciada por alguém? Caso tenha sido por vontade própria, por que a empresa despertou seu interesse?

Como você via a empresa antes e depois de assumir este cargo? O que mudou?

Suas decisões estavam baseadas sempre em informações, a partir da intuição ou por comportamento mimético?

Você percebe que o entendimento sobre a gestão era similar entre os membros ou diferente?

Sobre Sucessão

Como ocorre o processo e a escolha do(s) sucessor(es)?

Quais as principais dificuldades notadas por você no processo de sucessão? (Disputa de poder entre membros da família, resistência à mudança por quebrar hábitos e rotinas).

Para você, o que é mais importante em um processo de sucessão? 
Sobre Problemas Familiares

Em algum momento brigas entre os casais geraram conflito e tensões no ambiente de trabalho?

Quais eram as estratégias utilizadas pela empresa para enfrentar situações de estresse com relação aos conflitos familiares?

Por que houve a dissolução da sociedade?

Sobre Sentimentos

Quais foram as principais situações que geraram discordância e conflitos no trabalho?

Como lidavam com situações de sentimentos, emoção e paixão dentro da empresa?

O que poderia ter sido diferente para que não houvesse a dissolução da sociedade?

Como citar este artigo:

\section{ABNT}

VOGT, Mara; HAVEROTH, Juçara; ZONATTO, Vinícius Costa da Silva. Relações entre irmãos: impacto da rivalidade na gestão. RACE, Revista de Administração, Contabilidade e Economia, Joaçaba: Ed. Unoesc, v. 18, n. 1, p. 57-86, jan./abr. 2019. Disponível em: https://portalperiodicos.unoesc.edu.br/race. Acesso em: dia/mês/ano.

\section{APA}

Vogt, M., Haveroth, J., \& Zonatto, V. C. da S. (2019). Relações entre irmãos: impacto da rivalidade na gestão. RACE, Revista de Administração, Contabilidade e Economia, 18(1), 57-86. Recuperado de http://editora.unoesc.edu.br/index.php/race 